\title{
Overlap between general factors of psychopathology and personality: They share associations with daily life functioning and communication style
}

\author{
Dimitri van der Linden ${ }^{1}$ (D) Curtis S. Dunkel ${ }^{2} \cdot$ Peter Prinzie $^{1}$ (D) $\cdot$ Misa Yamanaka-Altenstein ${ }^{3} \cdot$ Agnes von Wyl $^{4}$ (D) \\ Michael P. Hengartner ${ }^{4}$ (D)
}

Accepted: 30 September 2021

(c) The Author(s) 2021

\begin{abstract}
Previous studies have shown that specific personality dimensions, -e.g., the Big Five-, consistently intercorrelate, such that they form a general factor of personality (GFP). It has been hypothesized that the GFP reflects social effectiveness. Similarly, in the clinical domain, overlap between various psychopathological symptoms has also been reported, leading to a general factor of Psychopathology, or $p$ factor. The aim of this study was to test the overlap between the higher-order factors in personality and psychopathology, and how they relate to daily life functioning and communication style. We tested a sample of 165 outpatients of a psychological therapy institute, using a multi-source approach that included self-reports and other ratings. The outpatients' self-reports of personality, general psychological problems, and interpersonal problems were available. Psychotherapists rated the outpatients' functioning in daily life with the well-known Global Assessment of Functioning (GAF) scale. A spouse or friend also rated the impact of the patient's communication/social behavior. Patients with lower GFP scores and higher scores on general psychopathology, displayed more distress and daily functioning deficits (i.e., lower GAF scores) and, in terms of communication styles, were also rated as being less dominant, less in control socially, and more submissive and aggressive. We proposed that part of the overlap between the general factors (GFP, psychopathology factors) may relate to a lower general life functioning and less social effectiveness.
\end{abstract}

Keywords General Factor of Personality $\cdot \mathrm{p}$ factor $\cdot$ Psychopathology $\cdot$ Life functioning $\cdot$ Social effectiveness

\section{Introduction}

In the past decade, there has been an upsurge of studies examining the overlap between psychological traits that traditionally have been considered to be largely independent from each other. In the domain of personality, much of this

Dimitri van der Linden

vanderlinden@essb.eur.nl

1 Department of Psychology, Education, \& Child Studies, Erasmus University Rotterdam, P. O. Box 9104, 1000 DR Rotterdam, The Netherlands

2 Department of Psychology, Western Illinois University, Macomb, USA

3 Klaus-Grawe-Institute for Psychological Therapy, Zurich, Switzerland

4 Department of Applied Psychology, Zurich University of Applied Sciences, Zurich, Switzerland research has been conducted under the label of the General Factor of Personality or GFP (Figueredo et al., 2004; Musek, 2007; Rushton et al., 2008; Van der Linden et al., 2010). The GFP emerges from the intercorrelations among specific personality traits and appears to capture the socially desirable poles of those traits. Translated in terms of the well-known Big Five model, this implies that persons scoring high on the GFP would, on average, be relatively open to new experiences, diligent (conscientious), sociable (extraverted), friendly (agreeable), and emotionally stable (Below we will elaborate on the nature of the GFP).

In the clinical domain, it has been acknowledged that many of the psychopathological syndromes such as depression, anxiety, psychosis, thought problems, and antisocial behavior also show considerable overlap (Caspi et al., 2014; Lahey et al., 2012). This was already known for decades. For example, in two renowned psychopathology instruments, the symptom checklist (SCL90) and its shorted form, the Brief Symptom Inventory (BSI), a general factor was identified, 
that is referred to as the global severity index (GSI; Derogatis \& Melisaratos, 1983). More recently, the notion of a general factor in psychopathology has been expanded by assuming that this factor is present in almost all psychopathological symptoms, regardless of the specific instrument used to measure them. This shared variance among symptoms is often referred to as the $p$ factor (e.g., Caspi et al., 2014; Selzam et al., 2018; Van Bork et al., 2017).

Research on the $p$ factor seems to have the potential to reconcile previous findings on symptom overlap. For example, constructs such as the global severity index in the SCL90 and BSI appear to be highly similar to the $p$ factor (Malloy-Diniz et al., 2021). This is corroborated by the finding that the $p$ factor loads strongly on most of the subscales of the SCL90 and the BSI (Oltmanns et al., 2018).

Initially, studies on the GFP and $p$ factor were conducted largely independently from each other. However, both lines of research have the same statistical and conceptual underpinnings. For example, in each domain, initial doubt was raised about the consistency or replicability of the general factor (e.g., Revelle \& Wilt, 2013; van Bork et al., 2017). Yet, subsequent research confirmed that in personality as well as in psychopathology, general factors indeed are consistently found in a wide variety of datasets, using different measurement instruments, in adults as well as in adolescents and children (Laceulle et al., 2015; Martel et al., 2017; Rushton \& Irwing, 2011; Snyder \& Hankin, 2017). Therefore, the scientific debates no longer focus as much on the existence of the GFP or $p$ factor, but rather on what these factors may represent. In order to address this question it is important to examine how common factors in personality and in psychopathology relate to each other, because their overlap may reveal information about their nature. Similarly, the extent to which the general factors are associated with a range of other-rated criterion-related measures may also contribute to their interpretation. In the present multiinformant study with outpatients who sought therapy, we will address those two points.

\section{Different Views on General Factors in Personality or Psychopathology}

In the literature it has become clear that there are strong scientific debates on the nature of the general factors in personality and psychopathology (e.g., Revelle \& Wilt, 2013; Van der Linden et al., 2016, 2017). One interpretation that has been put forward is that they merely represent statistical artifacts or measurement bias (Revelle \& Wilt, 2013; Van Bork et al., 2017) and thus may not be relevant to the understanding of personality or psychopathology. This artifact account assumes that the shared variance of personality traits or psychopathological symptoms may simply emerge due to social desirability or other response biases (Bäckström, et al., 2009). Even though this may seem a plausible explanation, there are now various studies suggesting that this artifact or bias perspective does not provide a comprehensive account of the empirical findings (for a review see, Caspi et al., 2014; Dunkel \& van der Linden, 2014; Van der Linden et al., 2016). To illustrate, in the field of personality it has been shown that the GFP relates to a wide range of objective and other-rated criteria such as job performance (Pelt et al., 2017), social status, and even mating or reproductive success (Van der Linden et al., 2018). Moreover, the GFP overlaps between self and other ratings (Rushton et al., 2009). ${ }^{1}$ The fact that the GFP relates to other-rated and objective variables implies that its scores "extend into the real-world', which is more in line with the substantive than the artifact account of the general factor.

Another type of artifact explanation of the GFP that has been posed is that it merely represents a summary of the variables of which it consists (Revelle \& Wilt, 2013). However, this boils down to the basic question of what actually causes the consistent correlations between lower-order dimensions. This question can never be answered based on statistical analyses alone, but should be addressed by examining the nature of the factor and its nomological network.

The specific details of the scientific debate on the nature of the GFP can be rather complex and extensive, and also include questions on how to interpret various statistical models (e.g., SEM, factor analysis). The statistical and conceptual arguments and counter arguments related to the GFP have already been extensively discussed in several recent papers and reviews (Musek, 2007; Revelle \& Wilt, 2013; Riemann \& Kandler, 2010; Van der Linden et al., 2016, 2017, 2021). Accordingly, it may not be useful to repeat all of those here. All in all, however, it can be concluded that there is now a large body of literature suggesting that the GFP cannot be simply put aside as an artifact, but seems to hold a relevant substantive component.

Similar to research on the GFP, there is a large body of research that has looked at the general factor in psychopathological symptoms in relationship to various objective and other-rated criteria, such as lower school achievement (Caspi et al., 2014), lower general intelligence (Lahey et al., 2015), an unfavorable financial situation (Patalay et al., 2015), and

\footnotetext{
1 There are Multitrait-Multimethod (MTMM) studies that found null effects regarding self-and other ratings of the GFP (e.g., Riemann \& Kandler, 2010). However, in each of these studies, effects of the GFP were tested after controlling for lower-order dimensions of personality. Given the assumption that the GFP partly manifest itself in the lower-order dimensions, such an analytic procedure would obviously take away true variance. It can be compared to testing the effect of the general cognitive ability factor (g) after taking out the effects of specific cognitive abilities.
} 
more delinquent behavior (Pettersson et al., 2016). It has also been shown that self and other-rated based general factors of psychopathology considerably overlap, which further indicates it is substantive (Oltmanns et al., 2018). Finally, evidence for a general factor of psychopathology has been confirmed using polygenic scores (Selzam et al., 2018) and molecular genetic analysis of several mental disorders (Pettersson et al., 2016). Overall, these previous findings are generally considered to indicate that a relevant share of the $p$ factor is substantive (Selzam et al., 2018; Snyder \& Hankin, 2017).

\section{Overlap between general factors?}

More recently, scholars have shown interest in the extent to which the GFP and general factors of psychopathology overlap. In a seminal study, Oltmanns et al. (2018) found correlations ranging from -0.70 to -0.90 between, on the one hand, the GFP, and, on the other hand, the $p$ factor, and a general factor that they extracted from measures of personality disorders (they labelled this as a general personality disorder factor). The overlap between the three factors was found using self-reports as well as other ratings. The authors also speculated on why those general factors may overlap.

"What all of these general factors might have in common, or perhaps how they should be understood, is that they simply reflect the extent of impairment or dysfunction within the respective persons' lives, irrespective of the basis for that dysfunction or impairment, whether it be from the presence of a mood disorder, a psychosis, a PD, or a personality trait." (Oltmanns et al., 2018, p. 587)

One of the reasons that the authors emphasized the speculative nature of their ideas was that their study did not include other-rated assessment of the participants' daily impairment or dysfunction. Thus, they could not empirically test their ideas regarding general impairment. In present study, however, we go beyond this previous research by directly conducting this test.

Specifically, in a sample of outpatients who sought therapy for psychological problems, we will test whether general factors in different domains (i.e., personality, psychopathology) indeed relate to the overall ability to deal with various life domains. We included 1) the GFP, 2) a valid proxy of the $p$ factor-, and 3 ) a general factor in personality disorders, similar to one used in Oltmanns et al. (2018). We tested whether these three general factors associate with the patients' global assessment of functioning (GAF; Hall, 1995) as rated by the participants' therapists. This is important because the GAF score is a well-known clinical instrument used by mental health professionals to assess the patients' general social, occupational, and psychological functioning.

In their molecular genetic study on the general factor of psychopathology, Pettersson et al. (2016) already stated: "We proffer an additional speculation, namely that the general factor measures overall distress or impairment, akin to the Global Assessment Functioning index..." (p. 720). Yet, they also did not directly test this hypothesis. We agree, however, that in as far as the overlap between the general factors indeed reflects overall impairment or dysfunction in meeting various problems-in-living (Oltmanns et al., 2018) then the GAF scores can be expected to relate to all three factors.

To our knowledge, direct tests of the relations between GAF and general factors of psychopathology have not been conducted before. Yet, doing so can contribute to further insight into the nature of the general factors and their overlap (Caspi et al., 2014).

Any overlap between the GAF and the general factor in psychopathological problems may seem obvious, because the GAF scores take into account the effect of psychopathological problems (see description in Table 2). Nevertheless, several decades ago, the GAF has been introduced in the clinical practice, precisely because it provides a unique source of information that is focused on how a person actually functions in daily life. In this sense, it would allow a direct empirical tests of the predictions formulated by Oltmanns et al. (2018) and Pettersson et al. (2016).

Tests on the associations between the GFP and GAF may be even more revealing, because the GFP is usually extracted from traits that represent the normal-range personality distribution. Nevertheless, based on the notion that lower GFP scores may indicate psychological problems (Figueredo et al., 2004), a positive GFP-GAF association can be expected. Again, to our knowledge, no previous studies have directly tested the association between GFP and GAF scores. All in all, the reasoning above leads to the following Hypothesis:

H1: The GFP is positively related to the patients' GAF scores, whereas the general factors in psychopathology and personality disorders are negatively related to GAF scores.

A second, and related aim of the present study was to assess the relationship between the general factors and the socalled impact of communication, which entails how a person's behavior and communication style are experienced by others (Schmidt et al., 1999). The rationale for including tests of the participants' impact on others is based on the notion that general social (in)effectiveness may be one of the mechanisms causing the GFP and general psychopathology/interpersonal problem factors to be linked (Oltmanns et al, 2018; Rushton $\&$ Irwing, 2011). For example, one of the leading substantive 
theories on the GFP is that it mainly reflects social effectiveness (Dunkel \& Van der Linden, 2014; Loehlin \& Martin, 2011; Van der Linden et al., 2016). This theory implies that individuals with high scores on the GFP have better social and communicative knowledge and have the skills and motivation to use that knowledge in order to achieve their personal goals (e.g., building social relations, doing well at work, finding a romantic partner). As humans are social animals by nature, it may not be difficult to perceive how being low on social effectiveness could have a pervasive detrimental impact on various life domains leading to a generalized dysfunctionality captured in high general scores on psychopathology and lower scores on socially desirable personality traits.

The theory of the GFP as social effectiveness is supported by findings showing a strong overlap with measures of emotional intelligence (Van der Linden et al., 2017) and its relation to emerging leadership (Pelt et al., 2017, Wu et al., 2020). Accordingly, at least a part of the overlap between the GFP and general factors of psychopathology may lie in compromised interpersonal or social skills. One typical consequence of being socially ineffective is that it tends to associate with a more negative impact on others. To test this presumed aspect of social effectiveness, we use a well-known clinical instrument that measures impact of communication/ social behavior, namely the Impact Message InventoryCircumplex (Hall, 1995). In that test, others rate the impact that the participants' interpersonal behavior has on them. The impact message instrument contains different subscales that indicate positive social impact -e.g., friendly, friendlydominant- whereas other subscales indicate a negative social impact -e.g., submissive, hostile-dominant- social impact (see Method section). Overall, we expect the following:

H2: The GFP will be associated with a positive profile of impact on others, whereas the general BSI and interpersonal problems factors will associated with a more negative profile of impact.

In conclusion, the present study may contribute to insight into why the general factors in the personality and psychopathology domain overlap. In addition, by having three self-report measures including normal-range personality and mental problems, and two other-rated measures from different sources (i.e., the therapist and one person who is close to the participant) it is possible to address parts of the artifact-substantive interpretations.

\section{Method}

\section{Participants and procedures}

In the present study, we used the sample described in the published pre-registered protocol of Hengartner and
Yamanaka-Altenstein (2017), and which consists of 165 outpatients (113 females, 52 males) from a psychological therapy institute. All participants were Caucasian. The educational level of the participants were: primary school (1.8\%), secondary school (13.3\%), high school (10.9), higher education (15.2), or University (55.2\%). Most of the participants $(67.3 \%)$ were in a relationship $(32.71 \%$ was married). All participants were between 18 and 65 years of age $(M=30.02$ years, range $18-65$ years $)$ and were receiving psychotherapy. The type of therapy the participants received was individually tailored, based on their specific complaints and needs, but the main focus was on cognitivebehavioral and interpersonal techniques. The types of mental health problems of the participants were heterogeneous and included, but were not restricted to, depression, general anxiety disorder, burnout, post-traumatic stress disorder, substance uses disorders, and personality disorders. It is important to note that a substantial proportion of the participants $(n=81,49.1 \%)$ did not meet official criteria for a mental disorder. These participants sought psychotherapy mostly due to marital problems and other interpersonal problems. Among the 84 participants with a psychiatric diagnosis (50.9\%), the most common groups were anxiety and stressrelated disorders $(n=46)$ and depressive disorders $(n=30)$. All measures described below were assessed at the beginning of therapy, that is, in most cases between the first and second therapy session. All participants gave their informed consent and the study was approved by the Cantonal Ethics Committee of Zurich. The project was financially supported by a grant from theOPO foundation (reference number 2016-0038).

\section{Measures}

Normal-range personality Personality was assessed with the German version (Rammstedt \& Danner, 2017) of the validated self-report Big Five Inventory (BFI; John, \& Srivastava, 1999). The BFI consists of 42 items that are answered on a 5-point Likert scale and that make up the dimensions of the Five Factor Model of Personality: Openness to new experiences $(\mathrm{O})$, Conscientiousness $(\mathrm{C})$, Extraversion (E), Agreeableness (A), and Neuroticism (N). Reliabilities (alpha) of the scales were $0.81,0.82,0.85,0.73$, and 0.83 , for $\mathrm{O}, \mathrm{C}, \mathrm{E}, \mathrm{A}$, and $\mathrm{N}$, respectively.

Subjective psychopathological symptoms The participants' psychopathological symptoms were measured with the German translation (Geisheim et al., 2002) of the Brief Symptom Inventory (BSI: Derogatis, \& Melisaratos, 1983) a 53 item self-report survey. The BSI measures symptoms form nine psychopathological domains, namely somatization (S), obsessive-compulsive (OC), low interpersonal sensitivity (IS), depression (D), anxiety (A), hostility (H), phobic 
anxiety (PA), paranoia ideation (PI), and psychoticism (P). As the present study was a naturalistic observational study that partly utilized the routine data that are assessed for treatment supervision, we could obtain the participants' scale scores on this instrument from the institute, but did not have access to the raw (item level) data. Therefore, in contrast to the personality measures that we specifically added for this study, we could not directly calculate the sample reliabilities for this instrument and subsequent instruments (see below). Nevertheless, the BSI is known to be a reliable and valid instrument, used in many psychotherapy institutes around the world (Derogatis \& Fitzpatrick, 2004). The German version has also been widely used for decades in (sub) clinical settings. For example, in a large and German sample of 1252 outpatients receiving cognitive-behavioral therapy, Geisheim et al. (2002) reported reliabilities of the subscales ranging from $\alpha=0.70$ to 0.89 , with a Cronbach's alpha of 0.96 for the Global Severity Index.

Interpersonal problems One of the standard instruments that the institute uses to monitor treatment is the (German version [Brähler et al., 1999] of the) Inventory of Interpersonal Problems (IIP; Horowitz \& Strack, 2010). This 64 item scale assesses self-reported interpersonal problems captured in eight domains, namely, domineering (Do), vindictive (Vi), cold (Co), socially avoidant (SoA), submissive ( $\mathrm{Su}$ ), exploitable (Ex), overly nurturant ( $\mathrm{ONu}$ ), and intrusive (In). The instrument is widely used as a screening instrument in psychological and psychiatric research. We could only obtain the scales scores of the participants from the institute, therefore we could not report the direct reliabilities. Yet, similar to the BSI, the IIP is a well-known and often-used clinical instrument. Moreover, various studies have used and confirmed the validity and reliability of the German version of the scale. For instance, using a similar Swiss sample of 395 outpatients, Grosse Holtforth et al. (2006) reported subscales internal reliabilities ranging from $\alpha=0.71$ to 0.85 .

The scale scores of the IIP allowed us to also test for a general factor in this measure of psychological (interpersonal) problems.

Impact on others (other-rated) The impact of the participants on others was measured with the German version (Werner, 1984) of the Impact Message Inventory- Circumplex (IMI-C). The IMI-C consists of 56 items that have to be answered on a 4 point Likert Scale, ranging from 1 'Not at all' to 4 'Very much so'. The IMI-C is an instrument in which the person who fills in the survey indicates the impact on him/herself of the communication/interaction with the target person. In the present study, it indicates the impact the participants had on others. The persons who filled in the IMI-C in most of the cases were the partner/spouse or a family member of the participant. The IMI-C distinguishes the following eight domains: Dominance (D): Submissive (S), Hostile Dominance (HD), Friendly-Submissive (FS), Hostile (H), Friendly (F), Hostile Submissive (HS), and Friendly-Dominant (FD).

In the IMI-C two general communication styles can be extracted namely Agency, the extent to which one can influence others, and communion, the extent to which one is focused on relationships (Locke, 2011). Similar to the latter two instruments we could obtain the scale scores from the psychotherapy institute, but had no access to the item-level data. Therefore, we could not report psychometric details of the instrument. However, the IMI-C has shown to be reliable and valid instrument that is widely used in clinical practice. Recently, Caspar et al. (2016) re-evaluated the validity of the German version of the IMI-C and reported good reliabilities ranging from 0.68 to 0.86 for the different subscales in clinical samples.

General functioning in everyday life (therapist rated) The extent to which the participants' various life domains were disturbed by their psychological symptoms was estimated by the psychotherapists who treated them and who scored their patients on the Global Assessment of Functioning (GAF) scale (Hall, 1995). The GAF represents a single score ranging from 1 to 100 that captures how well the patient can deal with various social, occupational, and other life problems. Table 2 displays the meaning of the GAF scores and show that higher scores indicate better functioning.

\section{Statistical analysis}

The literature shows that there are different methods of extracting general factors from correlated variables (e.g., Jensen, 1998). These methods range from directly extracting the first unrotated factor scores, using exploratory factor analysis methods, such as Principal Axis Factoring (PAF), ${ }^{2}$ to using confirmatory factor analysis (CFA). Each method has its advantages and limitations. However, it has also been confirmed that, regarding general factors, the overall findings are quite robust for extraction method. The latter has been shown to apply to the general factor in the cognitive domain as well as the general factor in personality (Van der Linden et al., 2017).

Accordingly, from each domain we used the first unrotated factor (using principal axis factoring: PAF) extracted from the designated measures as operationalization of the general factors in this study. This method has been used in many previous studies (e.g., Figueredo et al., 2004; Jensen, 1998; Loehlin and Martin, 2011; Musek, 2007). In this

\footnotetext{
${ }^{2}$ In the literature, Principal Component Analysis (PCA) has been argued to be suboptimal for extracting latent factors.
} 
approach, the participants' scores on the general factors reflects the sum of their standardized scores on specific scales, multiplied by the factor loading of the general factor. Given the current sample size, this statistical method is the most straightforward approach that facilitates the interpretation of the findings.

In line with the previous statements of Jensen and Weng (1994) and Van der Linden et al. (2017), we also wanted to confirm empirically the robustness of the statistical method. Therefore, we also extracted the general factors using CFA/ SEM. The details of those analyses are reported in the supplementary material, but we report the general outcomes (i.e., correlations between factors) of this approach also in the Results section.

\section{Results}

\section{Basic tests of the general factors}

Extracting the unrotated first factor (using PAF) from the normal-range personality measures confirmed the presence of a viable GFP. The factor explained $34.74 \%$ of the variance in the Big Five dimensions (Eigenvalue $[\mathrm{EV}]=1.74$ ), and showed the typical pattern of factor loadings (e.g., Van der Linden et al., 2010), in this case $0.24,0.51,0.53,0.38$, and -0.48 , for $\mathrm{O}, \mathrm{C}, \mathrm{E}, \mathrm{A}$, and $\mathrm{N}$, respectively. The GFP obtained with this approach, correlated $r=0.91$ with the latent GFP as extracted with CFA (see supplementary material). This, again, confirms the relative invariance of the GFP over different statistical techniques (e.g., Van der Linden et al., 2017).

It was already clear from the literature that the BSI contains a general psychopathology score, which is labelled the global severity index (GSI: Derogatis \& Melisaratos, 1983). This GSI represents the unweighted mean score of all its subscale scores. As such, it was not surprising that when using the PAF extraction method, a strong general factor emerged that correlated very strongly with the GSI $(r=0.87)$. The general factor in the BSI explained $62.08 \%$ of the variance in the underlying psychopathological domains $(\mathrm{EV}=5.59)$. Factor loadings were, 0.64, 0.83, 0.84, 0.88, $0.83,0.69,0.59,0.65$, and 0.85 , for $\mathrm{S}, \mathrm{OC}$, IS, D, A, H, PA, $\mathrm{PI}$, and $\mathrm{P}$, respectively. Similar to the situation in the personality measures, the general BSI factor correlated near unity with the general latent factor from the BSI as extracted with CFA ( $r=0.98$, see supplementary material).

One additional point we address here is to what extent the general BSI factor also represents the, even more general, $p$ factor as reported in the literature (Caspi et al., 2014). Because, we only had the BSI in this Study, we could not directly examine the BSI- $\mathrm{p}$ factor similarity within the current sample. Nevertheless, an informative alternative to address this question was available from the intercorrelation matrix as reported in the study of Oltmanns et al. (2018). In their study, they used a wide range of psychopathology scales to extract the $p$ factor, and those, among others, also included the BSI scales. Using CFA/SEM, the correlation matrix from Oltmann et al.'s study allowed us to test the BSI- $p$ factor overlap. The details of those analyses are provided in the supplementary material. The main findings were 1) that the full $p$ factor showed high loadings on most of the specific BSI scales (ranging from 0.76 to 0.86 ; $M_{\text {Loading }}=80.4$ ), and 2) the $p$ factor without including the BSI scales correlated $r=0.88$ with the general factor of the BSI. All in all, this provides empirical support for the notion that the general factor of the BSI is a very good proxy (i.e., indicator) of the more general $p$ factor as reported in the literature. This conclusion is in line with the recent study of Malloy-Diniz et al. (2021).

Regarding interpersonal problems, a salient general factor also emerged from the IIP that explained $50.7 \%$ of the variance and that showed substantial loadings on each of the specific dimensions with values of $0.40,0.62,0.66,0.78$, 0.85, 0.73, 0.69, and 0.58, for Do, Vi, Co, SoA, Su, Ex, $\mathrm{ONu}$, and In, respectively. Henceforward, we refer to this general factor as the GIF (General Interpersonal problems Factor). The GIF extracted with Principal Axis Factoring as described above, correlated $r=0.95$ with the latent GIF as extracted with CFA (described in the supplementary material).

Table 1 shows that, in line with previous studies, the different general factors showed substantial intercorrelations. The GFP was negatively related to the $B S I / p$ and GIF factors, -0.43 and -0.57 , respectively. The $B S I / p$ and GIF factor were positively correlated $(r=0.64)$.

\section{Descriptives of the IMI-C and GAF scores}

In the present study, the designated criterion-related variables were the other-ratings of general functioning and of the impact of the patients' communication style. Therefore, to facilitate the interpretation of the findings we first discuss the descriptive and nature of these other ratings.

The means and $S D$ s in Table 1 show that, regarding their impact on others, the participants scored relatively low on the dominance-related scales, -i.e., agency-, in comparison to their scores on scales involving friendliness -i.e., communion. Given the finding that, compared to males, females scored higher on communion (Multivariate $F[2,128]=4.53$, $p=0.01, F_{\text {Communion }}[1,129]=8.96, \mathrm{p}<0.01$, but not on agency, $F_{\text {Agency }}[1,129]=0.25, p=0.60$ ), we looked at the communion-based and agency-based scales in males and females separately. The results showed that, in the sample, males as well as females mainly had a friendly/communion impact on the others. 


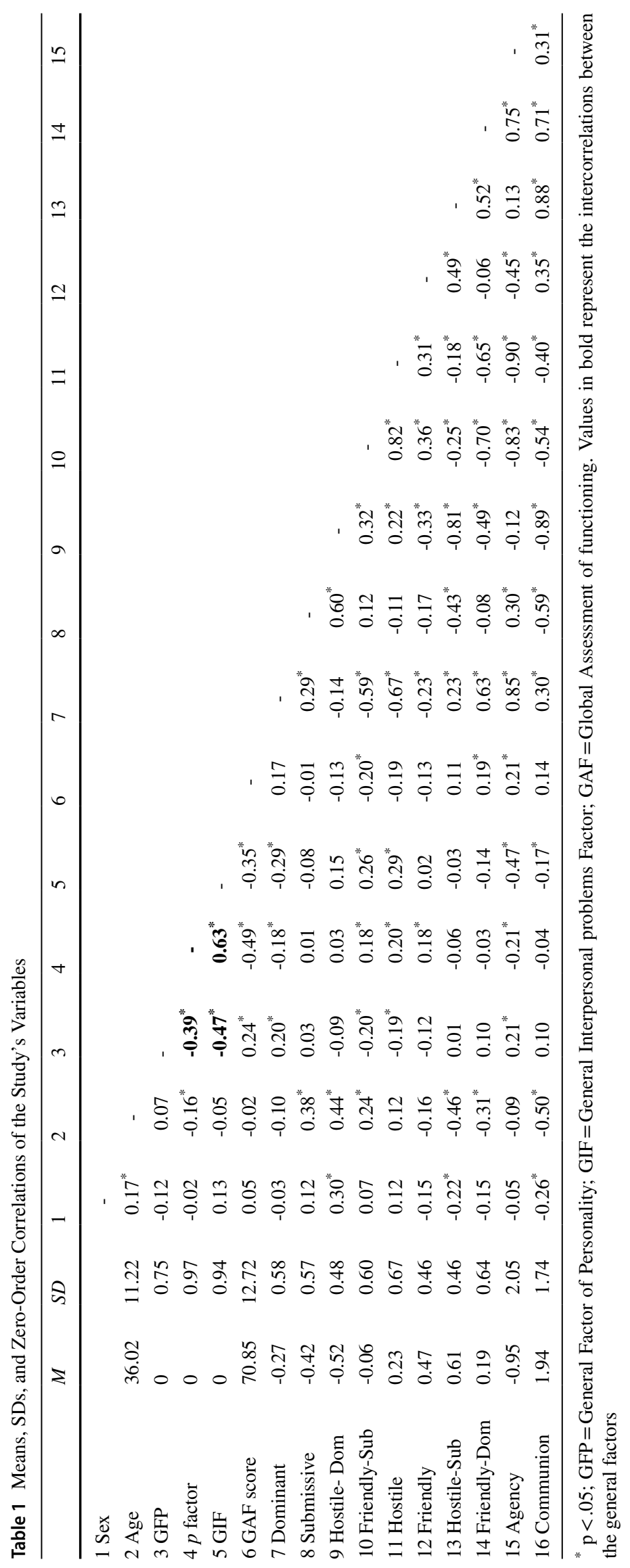


Table 2 Prevalence of GAF Scores and Description (Based on the Diagnostic and Statistical Manual of Mental Disorders; DSM-IV)

\begin{tabular}{|c|c|c|}
\hline GAF Score & $\begin{array}{l}\text { Prevalence \# } \\
\text { Participants } \\
\text { (and \%) }\end{array}$ & Description \\
\hline $91-100$ & $3(1.8 \%)$ & Superior functioning in most life domains \\
\hline $81-90$ & $29(17.6 \%)$ & Absent or mild symptoms. Good functioning in most areas of life \\
\hline $71-80$ & $44(27 \%)$ & $\begin{array}{l}\text { If symptoms are present they are transient and include reactions to clear stressors. Overall functioning is suf- } \\
\text { ficient (only slight impairments) }\end{array}$ \\
\hline $61-70$ & $49(30 \%)$ & $\begin{array}{l}\text { Mild symptoms, such as depressed mood, are present and some problems arise in various life domains (e.g., } \\
\text { social, occupational) }\end{array}$ \\
\hline $51-60$ & $28(17 \%)$ & $\begin{array}{l}\text { Moderate symptoms are present (e.g., panic attacks, flat mood) which are accompanied with moderate problems } \\
\text { in various life domains }\end{array}$ \\
\hline $41-50$ & $9(5.5 \%)$ & Serious symptoms are present (obsessions, suicidal ideation) or there serious problems in some life domains \\
\hline $31-40$ & $2(1.1 \%)$ & Impairments in reality testing and/or major impairments in life areas \\
\hline
\end{tabular}

The mean GAF score of around 70 displayed in Table 1 reveals that, on average, the participants functioned reasonably well in their life. However, the lowest score was 35 which indicates several severe problems with everyday life functioning. The highest score was 95 indicating excellent functioning in everyday life. Table 2 shows the number of participants per scoring category and a description of the level of functioning associated with the score-range.

\section{General factors and other-ratings}

Due to the associations of various key variables with sex and age, we tested the Hypotheses controlling for those demographic variables. Table 3 shows that Hypothesis 1 was confirmed, because the GFP was positively correlated with GAF scores, whereas the BSI/p factor and the GIF were significantly negatively related to it.

Regarding the impact on others, the GFP was significantly and positively related to being dominant and being friendly

Table 3 Correlations between GAF and Communication Impact with the General Factors (Controlling for Sex and Age)

\begin{tabular}{llll}
\hline & GFP & $p$ Factor & GIF \\
\hline 1 GAF & $0.17^{*}$ & $-0.47^{*}$ & $-0.45^{*}$ \\
2 Dominant & $0.21^{*}$ & $-0.26^{*}$ & $-0.35^{*}$ \\
3 Submissive & 0.03 & 0.06 & -0.11 \\
4 Hostile- Dom & -0.13 & $0.17^{*}$ & $0.17^{*}$ \\
5 Friendly-Sub & $-0.22^{*}$ & $0.29^{*}$ & $0.31^{*}$ \\
6 Hostile & $-0.23^{*}$ & $0.29^{*}$ & $0.32^{*}$ \\
7 Friendly & -0.08 & 0.16 & 0.06 \\
8 Hostile-Sub & 0.05 & -0.09 & -0.07 \\
9 Friendly-Dom & $0.17^{*}$ & $-0.25^{*}$ & $-0.27^{*}$ \\
10 Agency & $0.22^{*}$ & $-0.29^{*}$ & $-0.35^{*}$ \\
11 Communion & 0.15 & $-0.21^{*}$ & $-0.19^{*}$ \\
\hline
\end{tabular}

${ }^{*} p<.05 ; \mathrm{GFP}=$ General Factor of Personality; GIF $=$ General Interpersonal problems Factor; GAF $=$ Global Assessment of Functioning dominant, and negatively related to being friendly-submissive, and hostile. The BSI/ $p$ factor and the GIF basically showed the same pattern, but reversed, although GIF also negatively related to hostile dominance. All factors were significantly correlated with higher-order scores of agency (the GFP positively, the others negatively), whereas the GIF also significantly and negatively related to communion. Overall, the findings on the communication impact instrument were largely in line with Hypothesis $2 .^{3}$

\section{General versus specific personality factors}

With regard to the GFP, one question that is often raised is how it relates to its underlying personality traits. As the GFP reflects the shared variance of these traits, it is by definition true that each specific trait consists of variance that is shared with other traits (the general part) and variance that is unique to the specific trait. Therefore, it is useful to distinguish these two sources of variance. Although, this topic was not a main theme in this study (we did not formulate hypotheses on it) we considered it informative to, nevertheless, test the influence of the different sources of variance by also taking into account the underlying traits (in this case, the Big Five). Such analyses contribute to the viability of the findings with the general factors described above.

The zero order correlations are reported in Table 4. These correlations show that extraversion, neuroticism, and conscientiousness significantly related to the BSI/p factor and the GIF, whereas openness and agreeableness did not. Next,

\footnotetext{
${ }^{3}$ Despite our age-range selection that age distribution was somewhat skewed with $70 \%$ being under 41 . Therefore, we conducted parallel analyses testing the factor overlap and hypotheses using a cut-off score based on the distribution tale. Those parallel analyses showed that even with the restricted age range, all conclusions remain identical.
} 
Table 4 Correlations betweenthe criteria and the Big Five and residuals of the Big Five

\begin{tabular}{|c|c|c|c|c|c|c|c|c|c|c|}
\hline \multirow[b]{2}{*}{$\mathrm{BSI} / p$} & \multicolumn{2}{|c|}{ Openness } & \multicolumn{2}{|c|}{$\begin{array}{l}\text { Conscientious- } \\
\text { ness }\end{array}$} & \multicolumn{2}{|c|}{ Extraversion } & \multicolumn{2}{|c|}{ Agreeableness } & \multicolumn{2}{|c|}{ Neuroticism } \\
\hline & -.01 & (.15) & $-.29^{* *}$ & (.02) & $-.33^{* *}$ & $(-.02)$ & -.01 & $\left(.24^{* *}\right)$ & $.48^{* *}$ & $\left(.27^{* *}\right)$ \\
\hline GIF & -.05 & (.13) & $-.29^{* *}$ & (.13) & $-.49^{* *}$ & $(-.13)$ & $-.20^{*}$ & (.09) & $.46^{* *}$ & (.12) \\
\hline GAF & -.05 & $\left(-.16^{*}\right)$ & $.31^{* *}$ & (.14) & $.18^{* *}$ & $(-.04)$ & .01 & $\left(-.17^{* *}\right)$ & $-.27^{* *}$ & $(-.10)$ \\
\hline Agency & .03 & $(-.10)$ & $.30^{* *}$ & $(.05)$ & $.48^{* *}$ & $\left(.32^{* *}\right)$ & -.14 & $\left(-.39^{* *}\right)$ & $-.22^{*}$ & $(.02)$ \\
\hline Communion & -.04 & $(-.09)$ & .08 & $(-.02)$ & .13 & $(.05)$ & $.19^{* *}$ & (.15) & -.01 & (.11) \\
\hline
\end{tabular}

Notes: BSI $/ p=$ general factor from the Brief Symptom Inventory; GIF = general interpersonal problems factor; GAF global assessment of functioning.

Values in bold and in brackets represent the correlations with the Big Five residuals after taking out the GFP ${ }^{* *} \mathrm{p}<.05,{ }^{* *} \mathrm{p}<.01$ we saved the standardized residuals of each of the Big Five, after taking out their GFP. As can be seen in Table 4, by doing so, all of the initial correlations were substantially reduced or even reversed direction.

To illustrate, in the zero-order correlations, neuroticism was positively and significantly correlated to the BSI/p factor and the GIF, and negatively and significantly related to the GAF score and agency. After, taking out the GFP variance, however, neuroticism was only significantly related to the BSI- $p$ factor, and no longer to the GIF, GAF, and Agency. Moreover, the neuroticism-BSI $p$ factor correlation was reduced by almost half (44\%) after taking out the GFP. In a few cases, the GFP seemed to have been a suppressor. For example, the unique variance of agreeableness showed more significant correlations with the other factors and criteria than the full agreeable score (which is a mix of unique and shared variance).

A final, and different approach to examining the relative contributions of the specific traits' shared and unique variance is by means of separate hierarchical regressions in which we entered the GFP as an independent variable in the first step, and the unique variance of each Big Five dimension in the second step. Note that in these analyses the explained variance in each step is important and not the individual beta weights.

With the BSI/p factor as dependent variable, we found that the GFP explained $18.5 \%$ of the variance $(F[1]=34.64$, $p<0.001$ ), whereas the unique Big Five dimensions in step 2 explained an additional $13.6 \%(F[4]=7.44, p<0.001)$. With the GIF as dependent variable, the GFP explained $32.7 \%$ $(F[1]=71.77, p<0.001)$ of the variance, and the unique Big Five variances explained another $7.4 \%(F[4]=4.44$, $p<0.01)$.

For Agency, the GFP explained a significant $13.6 \%$ $(F[1]=19.36, p<0.001)$ of the variance, but unique variance of the Big Five from step 2 explained even more, $21 \%$ $(F[4]=9.56, p<0.001)$. For Communion, neither the GFP (1.8\% variance; $F[1]=2.29, p=0.13)$ nor the Big Five in step $2(4.2 \%$ variance; $F[4]=1.33, p=0.26)$ explained significant proportions of the variance.
Overall, the regression analyses show that the GFP was responsible for the lion's shares of the overlap between personality on the one hand, and the BSI/p factor and GIF on the other hand. The exception of this general trend was for agency. For agency, the total unique aspects of the Big Five explained more variance than the GFP. Neither the GFP or the total unique variance of the Big Five were significantly predictive of communion.

\section{Discussion}

In the present study with 165 patients of a psychotherapy clinic, we, first, confirmed the substantial overlap between the general factor in normal range personality dimensions (the GFP) and general factors extracted from the Brief Symptom Inventory and interpersonal problems measures (a BSI $/ p$ factor and the GIF), respectively. The finding that the factors substantially overlap are fully in line with several previous studies on this topic (e.g., Oltmanns et al., 2018; Rushton \& Irwing, 2011).

Although the BSI covers the majority of psychopathological symptoms, we wish to note here that it does not include a full range of psychopathologies. For example, several externalizing disorders, ADHD, addiction and were not assessed. Subsequently, the general factor extracted from the BSI (similar to the global severity index) was based on an incomplete list of symptoms. Nevertheless, using the intercorrelation matrix as reported in Oltmanns et al. (2018), we could empirically confirm that the general factor from the BSI is a very good proxy for the more inclusive $p$ factor. This finding is in accordance with the indifference of the indicator principle, as has been reported in the cognitive and personality domains (Jensen, 1998; Van der Linden et al., 2017). For example, the general factor of intelligence can be extracted from a wide range of specific cognitive tests, and is assumed to reflect a very broad cognitive ability. Yet, very good estimates of the $g$ factor can be obtained based on a relative narrow range of cognitive tests, or sometimes even with one single test, such as the Raven matrices. Based 
on the data and literature, it can therefore also be assumed that the general factor of the BSI provides an adequate representation of the $p$ factor. This is further corroborated by the fact that it also strongly relates to the general factor of interpersonal problems.

In order to gain additional insight in the nature of the general factors and their commonality, we tested the factors in relation to two other-rated criterion measures, namely the global assessment of functioning (in life), -the GAF-, and the participants' impact on others.

In line with Hypothesis 1, we found that those participants scoring lower on GFP, and higher on $\mathrm{BSI} / p$ factor and GIF were, on average, also given lower GAF scores by their therapists. This finding fits with the notion that what the general factors have in common is an overall difficulty in dealing with various life domains. This finding can contribute to the existing literature, as to the best of our knowledge, they provide the first direct empirical test of the previous speculations by Oltmanns et al. (2018) as well as Pettersson et al. (2016).

The overlap between the GAF on the one hand, and the $\mathrm{BSI} / p$ factor and GIF on the other hand, is partly obvious because the GAF also includes ratings of the severity of psychopathological symptoms. However, the GAF scores contribute unique information on how well the participants are doing in everyday life in different domains and therefore contribute to knowledge on their commonality.

A major contribution, however, is that we found that the GFP shows a similar relationship, albeit in a reversed direction, to GAF scores. This latter finding endorses that a substantial part of the overlap between the GFP and general factors of psychopathology may lie in the difficulties in dealing with daily life.

Another question that was addressed in this study was how communication impact relates to the overlap between the general factors $(\mathrm{H} 2)$. This question was inspired by the notion that the GFP reflects social effectiveness (Loehlin \& Martin, 2011; Van der Linden et al., 2016). We found that higher GFP scores implied that the persons were considered to be more dominant and friendly dominant. To interpret this finding, one must realize that higher scores on dominance/ friendly dominance suggest that people have more influence on others, and might be better able to take charge in social situations. This also became apparent in the higher scores on the broader dimension of agency. The BSI $/ p$ factor and GIF basically showed the same pattern with communication impact, but, of course, in the reversed direction. We also wish to emphasize that higher GFP scores were not significantly associated with hostile dominance, and were even significantly negatively related to general hostility. Thus, the style of high-GFP individuals seems to be one of being able to take control, without disrupting relationships. Again, for higher scores on the $p$ factor and GIF this pattern was reversed: Those patients tended to have a more hostile and disruptive effect on others.

All in all, this pattern of findings seems to indicate that higher scores on the GFP and lower scores on the BSI $/ p$ and GIF factors indeed were accompanied with a more efficacious communication style. This finding is not a direct proof of the social effectiveness account, yet, it can reasonably be assumed that communication is a relevant aspect of socially effectiveness (Riggio et al., 2003).

Building on that idea, theoretically, it seems plausible that a general social effectiveness, or the lack thereof plays a relevant role in many psychopathological symptoms and life problems. This notion is in accordance with previous theorizing of Carver et al. (2017) who suggested that the $p$ factor may be understood in terms of difficulties controlling social behavior and emotions. In many life domains, success partly depends on the extent to which one relates to others (Brackett et al., 2011). Severe failures in adequate communication with others tends to have detrimental effects on one's occupational attainment and family or romantic relationships. The notion that communication, or social effectiveness in general, may be in common in general factors in personality and psychopathology, does not imply that there are no other processes involved. For example, Martel et al. (2017) found that, in children, higher scores on the $p$ factor were associated with less effective executive functions. Compromised executive functioning, which implies problems with inhibition, working memory, and cognitive flexibility, can also be expected to have a broad detrimental influence on various life domains. Another possible explanation that has been mentioned for the overlap between traits and psychopathology is general stress (Clark, 2005).

Establishing the relative contribution and the causal directions of different explanations would likely be complicated as most of them would probably be strongly intertwined. For example, compromised executive functioning can be expected to also harm social effectiveness and the outcome of that may be a general stress (e.g., due to repeated failures and compromising situations). Alternatively, experiencing much stress has been found to have a negative causal effect on executive control (Arnsten, 2009) and the ability to be socially flexible (McEwen \& Morrison, 2013).

Although the present findings provide some 'interesting pieces of the puzzle' that surrounds the debates on the general factors, there are limitations that need to be taken into account. First, the sample was limited in size and consisted of a rather specific group of people who actively sought treatment for their psychological complaints. This limits generalization. On the other hand, assets of the sample include the naturalistic setting and the presence of otherratings on two different measures. Another limitation is that, as we mentioned before, the measure of 'impact on others' only addresses a specific aspect of the social effectiveness 
hypothesis. For a clearer picture, future research should include a wider range of social effectiveness indicators such as whether or not someone really succeeds in obtaining social goals. A third limitation refers to the point we made earlier, namely that the general factor of the BSI is a proxy, albeit a good one, of the $p$ factor. Future research may want to examine general life functioning, communication style, and general social effectiveness and the $p$ factor using an even broader range of psychopathological symptoms.

Two additional limitations were 1) that we could not obtain the reliability scores of some of the surveys in the present study, and, 2) although we knew that each participant received therapy which a focus on cognitive-behavioral and interpersonal aspects, we did not know the exact content of the therapy for each outpatient. Regarding the reliabilities, it has to be noted, though, that each of the three tests (the BSI, IIP, and IMI-C) are well-validated and often-used clinical instruments. As such, the probability that the tests would have problematic psychometric properties in the current sample is low. With regard to the therapy, as the questionnaires were filled in at the very beginning of the patient's therapy, it cannot be assumed that the type or content of the therapy had a relevant effect on the basic correlations between the traits and outcomes measured at that point.

Further, in interpreting the present results, it is important to note that the existence of commonality in normal personality dimensions and psychopathological symptoms does not imply that more specific dimensions become obsolete. It is obvious that different people have different configurations of traits. And depending on the purpose of the assessment it can be useful to provide a detailed description of an individual (Ronald, 2019). Nevertheless, acknowledging that despite differential patterns, there may also be (a set of?) common processes that exert a broad influence on behavior may be useful to understand why many traits tend to correlate and why psychopathological symptoms typically show high comorbidity. Delineating the nature of a general factor in personality and psychopathology may help to understand why some people tend to experience problems across many of their life domains, whereas others seem to navigate through life relatively successfully.

Supplementary Information The online version contains supplementary material available at https://doi.org/10.1007/s12144-021-02354-7.

Funding The project was financially supported by a grant from the OPO Foundation (reference number 2016-0038).

Data availability The data that support the findings of this study are openly available in [Open Science Framework] at [https://osf.io/ ukbs5/], reference number [ukbs5].

\section{Declarations}

Ethical statement This study was carried out in accordance with the recommendations of the Cantonal Ethics Committee (KEK) of Zurich with written informed consent from all subjects. All subjects gave written informed consent in accordance with the Declaration of Helsinki. The protocol was approved by the Cantonal Ethics Committee of Zurich.

Conflicts of interest The authors have no conflict of interests or competing interests.

Open Access This article is licensed under a Creative Commons Attribution 4.0 International License, which permits use, sharing, adaptation, distribution and reproduction in any medium or format, as long as you give appropriate credit to the original author(s) and the source, provide a link to the Creative Commons licence, and indicate if changes were made. The images or other third party material in this article are included in the article's Creative Commons licence, unless indicated otherwise in a credit line to the material. If material is not included in the article's Creative Commons licence and your intended use is not permitted by statutory regulation or exceeds the permitted use, you will need to obtain permission directly from the copyright holder. To view a copy of this licence, visit http://creativecommons.org/licenses/by/4.0/.

\section{References}

Altenstein-Yamanaka, D., Zimmermann, J., Krieger, T., \& Dörig, N. (2017). Self-reported interpersonal problems and impact messages as perceived by significant others are differentially associated with the process and outcome of depression therapy. Journal of Counseling Psychology, 64, 410-423. https://doi.org/10.1037/ cou0000221

Arnsten, A. F. (2009). Stress signaling pathways that impair prefrontal cortex structure and function. Nature Reviews Neuroscience, 10 , 410.

Bäckström, M., Björklund, F., \& Larsson, M. R. (2009). Five-factor inventories have a major general factor related to social desirability which can be reduced by framing items neutrally. Journal of Research in Personality, 43, 335-344. https://doi.org/10.1016/j. jrp.2008.12.013

Brackett, M. A., Rivers, S. E., \& Salovey, P. (2011). Emotional intelligence: Implications for personal, social, academic, and workplace success. Social and Personality Psychology Compass, 5, 88-103. https://doi.org/10.1111/j.1751-9004.2010.00334.x

Brähler, E., Horowitz, L. M., Kordy, H., Schumacher, J., \& Strauß, B. (1999). Zur Validierung des Inventars zur Erfassung Interpersonaler Probleme (IIP)—Ergebnisse einer Repräsentativbefragung in Ost-und Westdeutschland. Psychotherapie Psychosomatik Medizinische Psychologie, 49, 422-431.

Carver, C. S., Johnson, S. L., \& Timpano, K. R. (2017). Toward a functional view of the $p$ factor in psychopathology. Clinical Psychological Science, 5, 880-889. https://doi.org/10.1177/ 2167702617710037

Caspar, F., Berger, T., Fingerle, H., \& Werner, M. (2016). Das deutsche IMI. PiD- Psychotherapie Im Dialog, 17(4), e1-e10. https://doi.org/10.1055/s-0042-105981

Caspi, A., Houts, R. M., Belsky, D. W., Goldman-Mellor, S. J., Harrington, H., Israel, S., ... \& Moffitt, T. E. (2014). The p factor: one general psychopathology factor in the structure of psychiatric disorders? Clinical Psychological Science, 2, 119-137. https://doi.org/10.1177/2167702613497473 
Clark, L. A. (2005). Temperament as a unifying basis for personality and psychopathology. Journal of Abnormal Psychology, 114, 505-521.

Derogatis, L. R., \& Melisaratos, N. (1983). The brief symptom inventory: An introductory report. Psychological Medicine, 13, 595-605. https://doi.org/10.1017/S0033291700048017

Derogatis, L. R., \& Fitzpatrick, M. (2004). The SCL-90-R, the Brief Symptom Inventory (BSI), and the BSI-18. In M. E. Maruish (Ed.), The use of psychological testing for treatment planning and outcomes assessment: Instruments for adults (pp. 1-41). Lawrence Erlbaum Associates Publishers.

Dunkel, C. S., \& Van der Linden, D. (2014). Evidence for the general factor of personality as social-effectiveness. Personality and Individual Differences, 64, 147-151. https://doi.org/10.1016/j. paid.2014.02.030

Figueredo, A. J., Vasquez, G., Brumbach, B. H., \& Schneider, S. M. (2004). The heritability of life history strategy: The k-factor, covitality, and personality. Social Biology, 51, 121-143. https:// doi.org/10.1080/19485565.2004.9989090

Geisheim, C., Hahlweg, K., Fiegenbaum, W., Frank, M., Schröder, B., \& von Witzleben, I. (2002). Das Brief Symptom Inventory (BSI) als Instrument zur Qualitätssicherung in der Psychotherapie. Diagnostica, 48, 28-36.

Grosse Holtforth, M., Lutz, W., \& Grawe, K. (2006). Structure and Change of the IIP-D Pre- and Postpsychotherapy. European Journal of Psychological Assessment, 22, 98-103. https://doi. org/10.1027/1015-5759.22.2.98

Hall, R. C. (1995). Global assessment of functioning: A modified scale. Psychosomatics, 36, 267-275. https://doi.org/10.1016/ S0033-3182(95)71666-8

Hengartner, M. P., \& Yamanaka-Altenstein, M. (2017). Personality, Psychopathology, and Psychotherapy: A Pre-specified Analysis Protocol for Confirmatory Research on Personality-Psychopathology Associations in Psychotherapy Outpatients. Frontiers in psychiatry, 8, 9. https://doi.org/10.3389/fpsyt.2017.00009

Horowitz, L. M., \& Strack, S. (2010). Handbook of interpersonal psychology: Theory, research, assessment and therapeutic interventions. John Wiley \& Sons.

Jensen A. R., (1998). The g factor: The science of mental ability. Praeger.

Jensen, A. R., \& Weng, L. J. (1994). What is a good g? Intelligence, 18, 231-258.

John, O. P., \& Srivastava, S. (1999). The Big Five trait taxonomy: History, measurement, and theoretical perspectives. Handbook of Personality: Theory and Research, 2(1999), 102-138.

Laceulle, O. M., Vollebergh, W. A., \& Ormel, J. (2015). The structure of psychopathology in adolescence: Replication of a general psychopathology factor in the TRAILS study. Clinical Psychological Science, 3, 850-860. https://doi.org/10.1177/2167702614560750

Lahey, B. B., Applegate, B., Hakes, J. K., Zald, D. H., Hariri, A. R., \& Rathouz, P. J. (2012). Is there a general factor of prevalent psychopathology during adulthood? Journal of Abnormal Psychology, 121, 971. https://doi.org/10.1037/a0028355

Lahey, B. B., Rathouz, P. J., Keenan, K., Stepp, S. D., Loeber, R., \& Hipwell, A. E. (2015). Criterion validity of the general factor of psychopathology in a prospective study of girls. Journal of Child Psychology and Psychiatry, 56, 415-422. https://doi.org/10.1111/ jcpp. 12300

Loehlin, J. C., \& Martin, N. G. (2011). The general factor of personality: Questions and elaborations. Journal of Research in Personality, 45, 44-49. https://doi.org/10.1016/j.jrp.2010.11.008

Locke, K. D. (2011). Circumplex measures of interpersonal constructs. In L. M. Horowitz \& S. Strack (Eds.), Handbook of Interpersonal Psychology (pp. 313-324). Wiley.

Malloy-Diniz, L. F., de Oliveira Serpa, A. L., de Souza Costa, D., Pinheiro, M. I. C., Diaz, A. P., de Paula, J. J., ... \& Silva, A. G.
(2021). Brief Symptoms Inventory psychometric properties supports the hypothesis of a general psychopathological factor. Trends in Psychiatry and Psychotherapy. In press.

Martel, M. M., Pan, P. M., Hoffmann, M. S., Gadelha, A., \& do Rosário, M. C., Mari, J. J., ... \& Rohde, L. A. . (2017). A general psychopathology factor ( $p$ factor) in children: Structural model analysis and external validation through familial risk and child global executive function. Journal of Abnormal Psychology, 126, 137. https://doi.org/10.1037/abn0000205

McEwen, B. S., \& Morrison, J. H. (2013). The brain on stress: Vulnerability and plasticity of the prefrontal cortex over the life course. Neuron, 79, 16-29. https://doi.org/10.1016/j.neuron.2013.06.028

Musek, J. (2007). A general factor of personality: Evidence for the Big One in the five-factor model. Journal of Research in Personality, $41,1213-1233$.

Oltmanns, J. R., Smith, G. T., Oltmanns, T. F., \& Widiger, T. A. (2018), General factors of psychopathology, personality, and personality disorder: Across domain comparisons. Clinical Psychological Science, 6, 581-589. https://doi.org/10.1177/2167702617750150

Patalay, P., Fonagy, P., Deighton, J., Belsky, J., Vostanis, P., \& Wolpert, M. (2015). A general psychopathology factor in early adolescence. The British Journal of Psychiatry, 207, 15-22. https://doi.org/10. 1192/bjp.bp.114.149591

Pelt, D. H., van der Linden, D., Dunkel, C. S., \& Born, M. P. (2017). The general factor of personality and job performance: Revisiting previous meta-analyses. International Journal of Selection and Assessment, 25, 333-346. https://doi.org/10.1111/ijsa.12188

Pettersson, E., Larsson, H., \& Lichtenstein, P. (2016). Common psychiatric disorders share the same genetic origin: A multivariate sibling study of the Swedish population. Molecular Psychiatry, 21,717 .

Rammstedt, B., \& Danner, D. (2017). Die Facettenstruktur des big five inventory (BFI): Validierung für die deutsche Adaptation des BFI. [The facet structure of the Big Five Inventory: Valdiation of the German Adaptation of the BFI]. Diagnostica, 63, 70-84.

Revelle, W., \& Wilt, J. (2013). The general factor of personality: A general critique. Journal of Research in Personality, 47, 493-504. https://doi.org/10.1016/j.jrp.2013.04.012

Riemann, R., \& Kandler, C. (2010). Construct validation using multitrait-multimethod-twin data: The case of a general factor of personality. European Journal of Personality, 24, 258-277.

Riggio, R. E., Riggio, H. R., Salinas, C., \& Cole, E. J. (2003). The role of social and emotional communication skills in leader emergence and effectiveness. Group Dynamics: Theory, Research, and Practice, 7(83), 258-277.

Ronald, A. (2019). The psychopathology p factor: Will it revolutionise the science and practice of child and adolescent psychiatry? Journal of Child Psychology and Psychiatry, 60, 497-499. https://doi. org/10.1111/jcpp.13063

Rushton, J. P., Bons, T. A., \& Hur, Y. M. (2008). The genetics and evolution of the general factor of personality. Journal of Research in Personality, 42, 1173-1185. https://doi.org/10.1016/j.jrp.2008. 03.002

Rushton, J. P., Bons, T. A., Ando, J., Hur, Y. M., Irwing, P., Vernon, P. A., Petrides, K. V., \& Barbaranelli, C. (2009). A general factor of personality from multitrait-multimethod data and cross-national twins. Twin Research and Human Genetics, 12, 356-365. https:// doi.org/10.1375/twin.12.4.356

Rushton, P., \& Irwing, P. (2011). The general factor of personality: Normal and abnormal. In T. Chamorro-Premuzic, S. von Stumm, \& A. Furnham (Eds.), The Wiley-Blackwell handbook of individual differences (pp. 132-161). Wiley-Blackwell.

Schmidt, J. A., Wagner, C. C., \& Kiesler, D. J. (1999). Psychometric and circumplex properties of the octant scale Impact Message Inventory (IMI-C): A structural evaluation. Journal of Counseling Psychology, 46, 325. https://doi.org/10.1037/0022-0167.46.3.325 
Selzam, S., Coleman, J. R., Caspi, A., Moffitt, T. E., \& Plomin, R. (2018). A polygenic $\mathrm{p}$ factor for major psychiatric disorders. Translational Psychiatry, 8, 205.

Snyder, H. R., \& Hankin, B. L. (2017). All models are wrong, but the p factor model is useful: Reply to Widiger and Oltmanns (2017) and Bonifay, Lane, and Reise (2017). Clinical Psychological Science, 5, 187-189. https://doi.org/10.1177/2167702616659389

Van Bork, R., Epskamp, S., Rhemtulla, M., Borsboom, D., \& van der Maas, H. L. (2017). What is the p-factor of psychopathology? Some risks of general factor modeling. Theory \& Psychology, 27, 759-773. https://doi.org/10.1177/0959354317737185

Van der Linden, D., te Nijenhuis, J., \& Bakker, A. B. (2010). The general factor of personality: A meta-analysis of Big Five intercorrelations and a criterion-related validity study. Journal of Research in Personality, 44, 315-327.

Van der Linden, D., Dunkel, C. S., \& Petrides, K. V. (2016). The General Factor of Personality (GFP) as social effectiveness: Review of the literature. Personality and Individual Differences, 101, 98-105. https://doi.org/10.1016/j.paid.2016.05.020

Van der Linden, D., Pekaar, K. A., Bakker, A. B., Schermer, J. A., Vernon, P. A., Dunkel, C. S., \& Petrides, K. V. (2017). Overlap between the general factor of personality and emotional intelligence: A meta-analysis. Psychological Bulletin, 143, 36. https:// doi.org/10.1037/bul0000078

Van der Linden, D., Dunkel, C. S., Figueredo, A. J., Gurven, M., von Rueden, C., \& Woodley of Menie, M. A. . (2018). How Universal Is the General Factor of Personality? An Analysis of the Big Five in Forager Farmers of the Bolivian Amazon. Journal of CrossCultural Psychology, 49, 1081-1097. https://doi.org/10.1177/ 0022022118774925

Werner, M. (1984). Das Impact Message Inventory: Ein interpersonaler personlich keitsfragebogen von Donald J. Kiesler (1976). Uebersetzung aus dem Amerikanischen und erste validierungen. Unpublished doctoral dissertation, University of Bern, Switzerland.

Wu, P., Van der Linden, D., Dunkel, C. S., van Vugt, M., \& Han, Q. (2020). Emerging leadership and the general factor of personality $(G F P)$ : A quasi-experimental test of an evolutionary prediction. Advanced Online Publication.

Publisher's Note Springer Nature remains neutral with regard to jurisdictional claims in published maps and institutional affiliations. 